\title{
Concise SAR Exploration Based on the "Head-to-Tail" Approach: Discovery of PI4KIIl $\alpha$ Inhibitors Bearing Diverse Scaffolds
}

Satoru Noji, ${ }^{\dagger}$ Noriyoshi Seki, ${ }^{\dagger}$ Takaki Maeba, ${ }^{\dagger}$ Takayuki Sakai, ${ }^{\dagger}$ Eiichi Watanabe, ${ }^{\dagger}$ Katsuya Maeda, ${ }^{\dagger}$ Kyoko Fukushima, ${ }^{\dagger}$ Toru Noguchi, ${ }^{\S}$ Kazuya Ogawa, ${ }^{\S}$ Yukiyo Toyonaga, ${ }^{\S}$ Tamotsu Negoro, Hisashi Kawasaki, ${ }^{\dagger}$ and Makoto Shiozaki*, ${ }^{\dagger}$

${ }^{\dagger}$ Chemical Research Laboratories, ${ }^{\S}$ Biological Pharmacological Research Laboratories, and Drug Metabolism \& Pharmacokinetics Research Laboratories, Central Pharmaceutical Research Institute, Japan Tobacco Inc., 1-1, Murasaki-cho, Takatsuki, Osaka 569-1125, Japan

\section{Supporting Information}

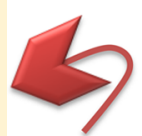

Head
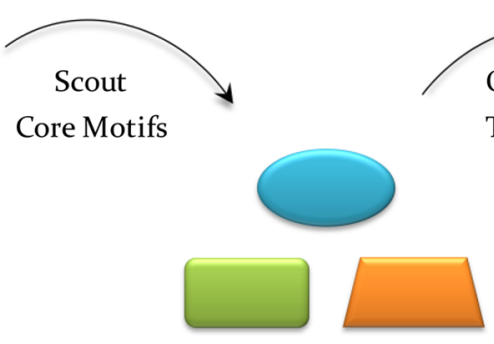

Core

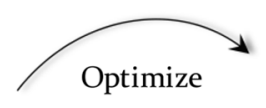

Tail Motifs

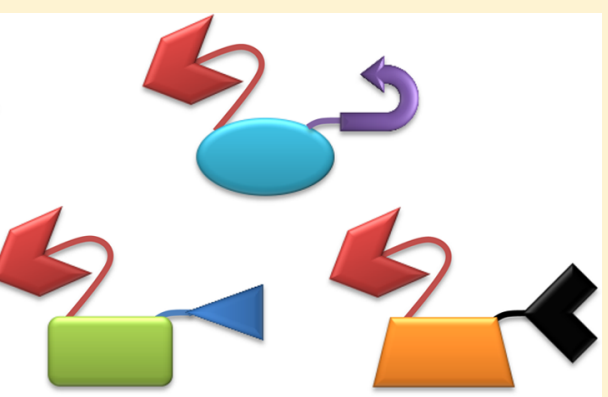

Diverse Set of Kinase Inhibitors

ABSTRACT: In typical kinase inhibitor programs, a hinge binder showing best potency with preferential specificity is initially selected, followed by fine-tuning of the accompanying substituents on its core module. A shortcoming of this approach is that the exclusive focus on a single chemotype can endanger all the analogues in the series if a critical shortcoming is revealed. Thus, an early evaluation of structure-activity relationships (SARs) can mitigate unforeseen outcomes within a series of multiple compounds, although there have been very few examples to follow such a policy. PI4KIII $\alpha$ is one of four mammalian phosphatidylinositol-4 kinases and has recently drawn significant attention as an emerging target for hepatitis $\mathrm{C}$ virus (HCV) treatment. In this letter, a novel "head-to-tail" approach to discover a diverse set of PI4KIII $\alpha$ inhibitors is reported. We believe this method will generate distinct core scaffolds, a rational strategy to circumvent potential risks in general kinase programs.

KEYWORDS: HCV, PI4KIII $\alpha$, head-to-tail approach, diverse scaffolds

$\mathrm{H}$ epatitis $\mathrm{C}$ virus $(\mathrm{HCV})$ is a leading cause of chronic liver disease, and 130-150 million people are considered to be infected worldwide. ${ }^{1,2}$ Patients with persistent infection of HCV are at high risk to develop serious liver damage typified by hepatocellular carcinoma, which can eventually necessitate liver transplantation. ${ }^{3,4}$ Although the therapeutic options are being improved after the approval of newly developed direct acting antivirals, ${ }^{5}$ significant concerns remain about drug resistance as well as inadequate coverage of all existing HCV genotypes. Due to these unmet needs, development of a new broad-spectrum antiviral strategy managing such potential problems are of great importance. To achieve such goals, the disruption of the viral lifecycle is a viable option so that several host proteins, which are implicated in HCV reproduction, have been intensely pursued. $^{6}$

PI4KIII $\alpha$ is known as one of four mammalian phosphatidylinositol-4 kinases and is responsible for formation of phosphatidylinositol 4-phosphate (PI4P) at cytoplasmic membranes, cis-Golgi compartments, and nucleus. ${ }^{7}$ One of the nonstructural HCV protein, NS5A, was reported to hijack the PI4P production machinery, which facilitates the viral replication by forming unique membranous web-like structures. Subsequently, silencing the PI4KIII $\alpha$ gene was confirmed to abrogate HCV's replication as well as its production. ${ }^{8,9}$ Therefore, a strategy targeting this enzyme is a rational approach for treatment of this virus based on the emerging mechanism of action.

While the concept of targeting this lipid kinase seems valid, one must take into account that interference with such an essential cellular function might cause some serious damage to the host cells themselves. Fortunately, there are other PI4 kinases such as $\operatorname{PI} 4 \mathrm{KIII} \beta$, which are responsible for maintenance of PI4P homeostasis, ${ }^{10}$ and thus specific inhibition of PI4KIII $\alpha$ holds great promise to suppress $\mathrm{HCV}$ replication

Received: June 7, 2016

Accepted: August 3, 2016

Published: August 3, 2016 
while keeping basal cell trafficking functions via PI4P intact through bypassing such redundant machinery.

Toward this end, we started a SAR investigation to obtain selective PI4KIII $\alpha$ inhibitors. Among the inhibitors reported to date, we focused our attention on compound 1 reported by a GSK research group ${ }^{11}$ since this compound showed good PI4KIII $\alpha$ inhibitory activity $\left(\mathrm{pIC}_{50}=8.3\right)$ with preferable selectivity over PI4KIII $\beta$ as high as 200 -fold (Figure 1 ).

The compound possessed a 2 -aminoquinazolinone skeleton as a hinge binder, on which a disubstituted pyridine and an atropisomeric benzene ring were attached. Although the selectivity profile of this compound was reasonably assured, we felt confident in implementing another core module having reduced affinity since the hinge domain is known to be a highly conserved region across many kinases. So, we decided to initiate investigation from its monodentate ${ }^{12}$ analogue 2 (Table 1) on which a simple benzene ring was implemented to avoid any stereoisomeric complications. To further mitigate an unexpected risk, ${ }^{13}$ we undertook an exploration of distinct classes of hinge-binding modules because we expected such an approach to subsequently result in generation of a diverse set of the inhibitors. In typical kinase programs, a hinge binder showing the best potency with preferential specificity is initially recruited, followed by fine-tuning of the substituents on this core motif. A shortcoming of such a classical approach is the excessive commitment to a sole chemotype, which, once a critical problem is revealed during the screening, could endanger further investigation of all the corresponding congeners. It is quite evident that a wide variety of compounds will be generated if the core scaffold can be modified, particularly if there are numerous potential substituents available. Aside from the hinge region, the affinity pocket ${ }^{14}$ is an ideal place to obtain good binding. Therefore, as the initial step of our investigation, we searched for a motif that displayed a favorable affinity for this pocket.

To gain a structure-based inspiration, a homology model of PI4KIII $\alpha$ was generated by using MOE (Chemical Computing Group, Montreal, Canada) using the known crystal structure ${ }^{15}$ of PI3K $\gamma$ as a template (Figure $2 \mathrm{a}$ ). Compound $\mathbf{2}$ was placed manually into the ATP-binding pocket of PI4KIII $\alpha$ with the 1nitrogen atom of the quinazolinone acting as a hinge binder, and the other parts of the molecule forming hydrophobic contacts in the pocket. The resultant complex model suggested that the substituted pyridine moiety of $\mathbf{2}$ projected toward a site corresponding to the affinity pocket so that exploration of this part of $\mathbf{2}$ was prioritized. In the preceding paper, the GSK group reported that reversal of the aminosulfonyl linkage resulted in an improvement of potency against $\operatorname{PI} 4 \mathrm{KIII} \alpha,{ }^{11}$ and so we synthesized two analogues having the reversed orientation ( 3 and 4 , Table 1 ). The results provided quite a contrast. Compound 3 showed significant improvement in

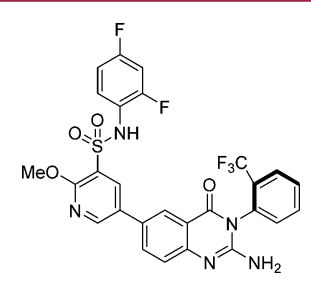

1

Figure 1. Structure of PI4KIII $\alpha$ inhibitor reported by GSK.
Table 1. SAR of the Head Motif
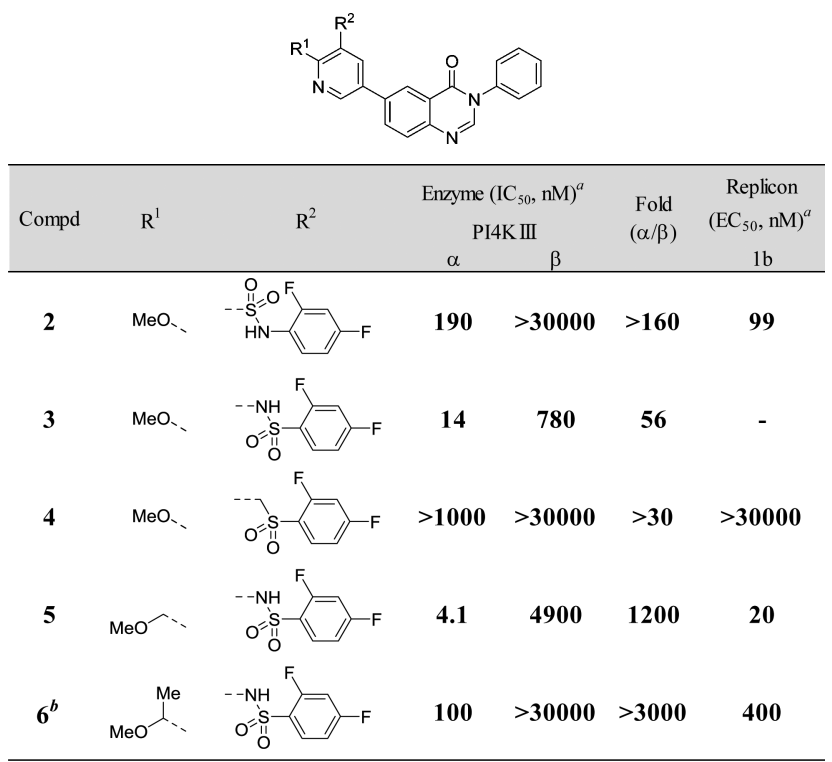

${ }^{a}$ Values of $\mathrm{IC}_{50}$ and $\mathrm{EC}_{50}$ are mean values determined from at least three replicates. ${ }^{b}$ Racemic.

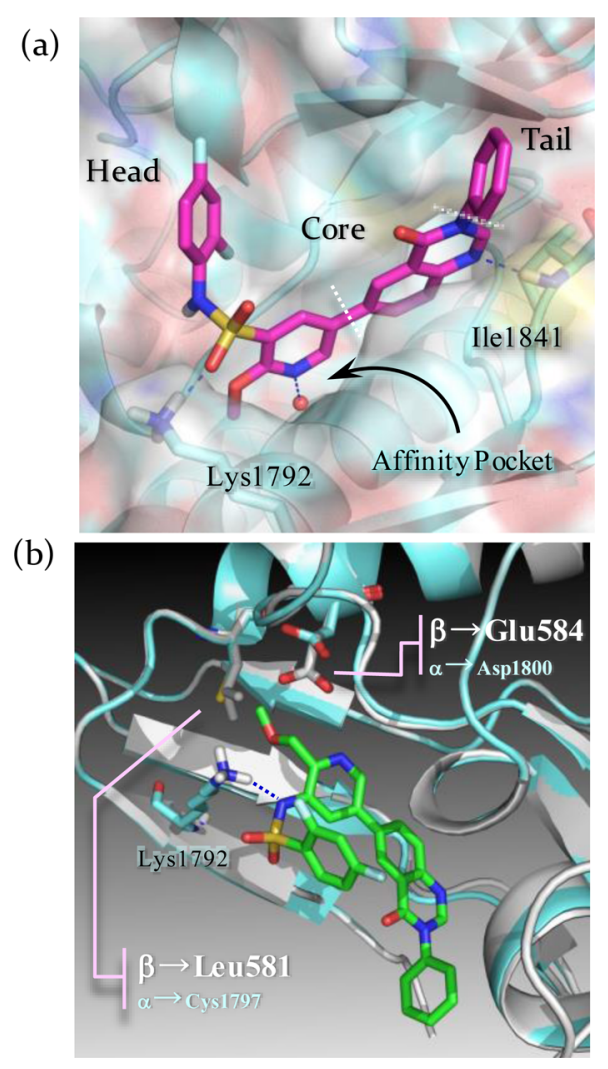

Figure 2. (a) PI4KIII $\alpha$ homology model with compound 2 based on using the PI $3 \mathrm{~K} \gamma$ crystal structure as a template. (b) Comparison of the affinity pocket of PI $4 \mathrm{KIII} \alpha$ (cyan) and $\operatorname{PI} 4 \mathrm{KIII} \beta$ (white) with $\mathbf{5}$.

PI4KIII $\alpha$ inhibitory potency, while its sulfone analogue 4 showed complete loss of the potency. It is quite plausible that the $\mathrm{NH}$ part of the sulfonamide moiety acquired a crucial electrostatic interaction with some residues in the pocket, suggesting that the exploration of core motifs could be feasible once we strengthened the compound's PI4KIII $\alpha$ selectivity without losing its robust potency. Actually, our homology and 
Table 2. SAR of the Core Motif

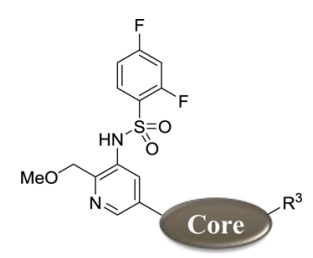

\begin{tabular}{|c|c|c|c|c|c|c|}
\hline Compd & Core & $\mathrm{R}^{3}$ & Enzym & $\begin{array}{l}\left.\mathrm{C}_{50}, \mathrm{nM}\right)^{a} \\
\mathrm{KIII}\end{array}$ & $\begin{array}{c}\text { Fold } \\
(\alpha / \beta)\end{array}$ & $\begin{array}{c}\text { Replicon } \\
\left(\mathrm{EC}_{50}, \mathrm{nM}\right)^{a}\end{array}$ \\
\hline 5 & & & 4.1 & 4900 & 1200 & 20 \\
\hline 7 & & & 8.0 & 8200 & 1030 & 68 \\
\hline 8 & & & 2.2 & 1400 & 640 & 41 \\
\hline 9 & & & 9.1 & 200 & 22 & 610 \\
\hline 10 & & & 13 & 410 & 32 & 880 \\
\hline 11 & & & 50 & 3700 & 74 & 1000 \\
\hline 12 & & & 93 & $>10000$ & $>110$ & 780 \\
\hline 13 & & & 260 & 18000 & 96 & 700 \\
\hline 14 & & & 3.1 & 98 & 32 & 50 \\
\hline 15 & & & 2.0 & 39 & 20 & 29 \\
\hline 16 & & & 16 & 920 & 58 & 78 \\
\hline 17 & & & 5.7 & 300 & 53 & 31 \\
\hline
\end{tabular}

${ }^{a}$ Values of $\mathrm{IC}_{50}$ and $\mathrm{EC}_{50}$ are mean values determined from at least three replicates.

sequence comparison model pointed out a pocket adjacent to the methoxy group of 3 in PI4KIII $\alpha$. Compared to other closely related enzymes, this binding pocket was more spacious, suggesting that this difference in binding site might be a source of improved isomer selectivity. Driven by this hypothesis, we synthesized two compounds possessing a slightly larger substituent as the $\mathrm{R}^{1}$ group. Gratifyingly, compound 5 completely satisfied our expectation, and $>1000$-fold selectivity over PI4KIII $\beta$ along with further improvement of PI4KIII $\alpha$ inhibitory potency was achieved.

According to our homology model (Figure 2b), ${ }^{16}$ the methoxymethyl group of compound $\mathbf{5}$ may be forced too closely to the Glu584 and Leu581 residues of PI4KIII $\beta$. Contrastingly, their counterparts of PI4KIII $\alpha$ are Asp1800 and Cys1797, respectively, more compact amino acids that afford
Table 3. SAR of the Tail Motif
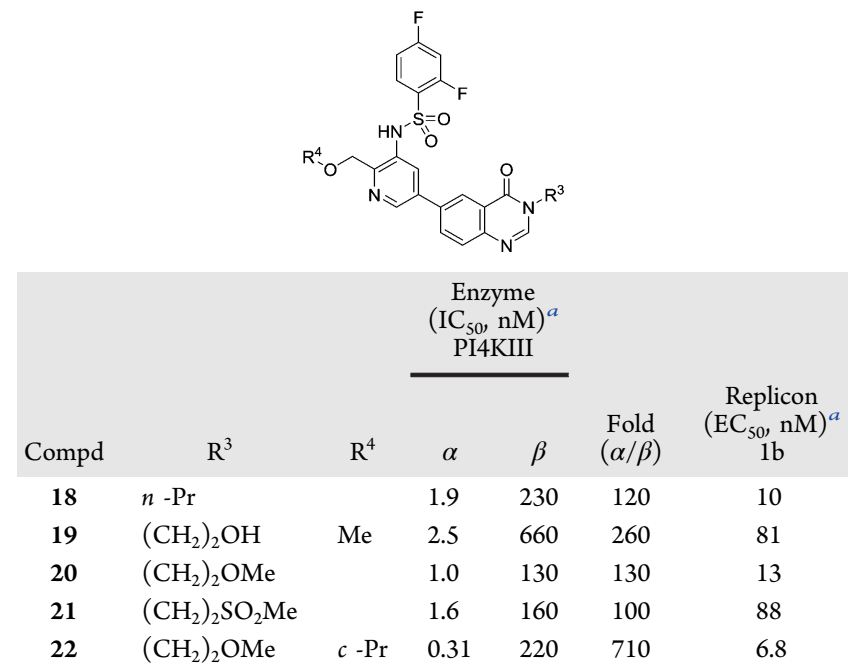

${ }^{a}$ Values of $\mathrm{IC}_{50}$ and $\mathrm{EC}_{50}$ are mean values determined from at least three replicates.

more room near the identical substituent of the inhibitor $\mathbf{5}$. Based on this analysis, we considered that the slightly larger two residues in PI4KIII $\beta$ would cause steric congestion, while a favorable hydrophobic contact between the Cys1797 of PI4KIII $\alpha$ and the terminal methoxy portion of 5 might have occurred. Moreover, the size of the methoxymethyl group was almost optimal, and compound $\mathbf{6}$ enlarged at a position adjacent to the pyridine ring showed significant loss of potency against either of the PI4KIII enzymes.

Since we had a suitable headgroup in hand, we embarked on an exploration of the core motif. We examined a diverse set of heterocycles whose substituents could project into a different location (Table 2). Rather surprisingly, compound 7 being almost identical to the reference compound $\mathbf{5}$ showed reduced PI4KIII $\alpha$ potency, while compound $\mathbf{8}$ whose $\mathrm{R}^{3}$ substituent was directed to a different vector showed comparable potency. Further dissimilar analogues having a 5,6-fused heteroaromatic group as the core unit generally showed reduced PI4KIII $\alpha$ potency (9-13). However, significant transformations of the $\mathrm{R}^{3}$ portion restored the inhibitory potency, allowing even the least potent analogue $\mathbf{1 3}$ to reach a single-digit nanomolar value of $\mathrm{IC}_{50}$ against PI4KIII $\alpha$ (17). It was also notable that the SAR trend of the $\mathrm{R}^{3}$ portion was different depending on the core modules (9 to 15 vs 13 to 17), suggesting that each core structure had a distinct preference for the accompanying tail portion $\mathrm{R}^{3}$. Following a typical optimization protocol, finetuning in the head and the tail region was complementarily conducted with one of the most potent compounds, 5 .

Starting from an analogue bearing a simple tail-like substructure (18), we introduced a functional group at the terminus (19-21) to lower the lipophilicity to increase the drug-like properties (Table 3). ${ }^{17}$ In accordance with the previous results represented by 15 and 17, compound 20 having an ether moiety showed better potency; by a slight modification of the headgroup (22), the PI4KIII $\alpha$ selectivity was further strengthened. Toward this end, we have successfully discovered a novel PI4KIII $\alpha$ inhibitor having superb PI4KIII $\alpha$ potency. This compound is composed of three new modules, the head, core, and tail groups, which are distinct from those of PI4KIII $\alpha$ inhibitors reported to date (It is also noteworthy that GSK reported that replacement of the benzene tail part with an 
Scheme 1. Synthesis of Diverse Sets of PI4KIII $\alpha$ Inhibitors ${ }^{a}$
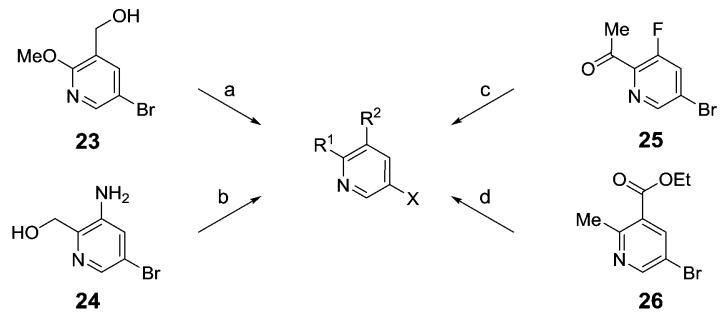

27: $\mathbf{R}^{1}=\mathrm{OMe}, \mathrm{R}^{2}=\mathrm{CH}_{2} \mathrm{SO}_{2}$ (2,4-di-F-Ph), $\mathrm{X}=\mathrm{Br}$ 28: $\mathrm{R}^{1}=\mathrm{CH}_{2} \mathrm{OMe}, \mathrm{R}^{2}=\mathrm{NHSO}_{2}(2,4-$ di-F-Ph), $\mathrm{X}=\mathrm{Br}$

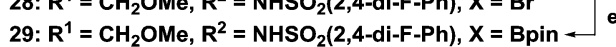
30: $\mathbf{R}^{1}=\mathrm{CH}(\mathrm{OMe}) \mathrm{CH}_{3}, \mathrm{R}^{2}=\mathrm{NHSO}_{2}(2,4-$ di-F-Ph), $\mathrm{X}=\mathrm{Br}$ 31: $\mathbf{R}^{1}=\mathrm{CH}_{2} \mathrm{Oc}-\mathrm{Pr}, \mathrm{R}^{2}=\mathrm{NHSO}_{2}(2,4-\mathrm{di}-\mathrm{F}-\mathrm{Ph}), \mathrm{X}=\mathrm{Bpin}$
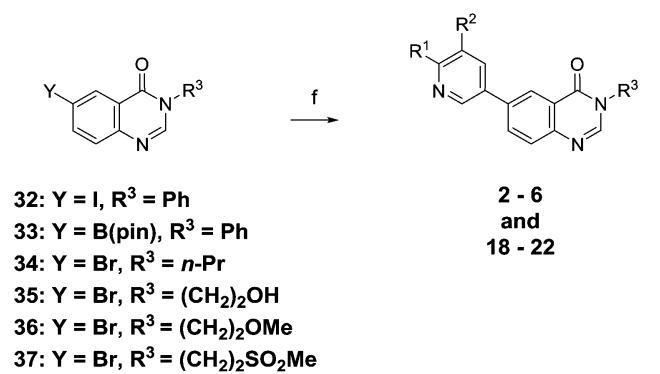

37: $\mathrm{Y}=\mathrm{Br}, \mathrm{R}^{3}=\left(\mathrm{CH}_{2}\right)_{2} \mathrm{SO}_{2} \mathrm{Me}$
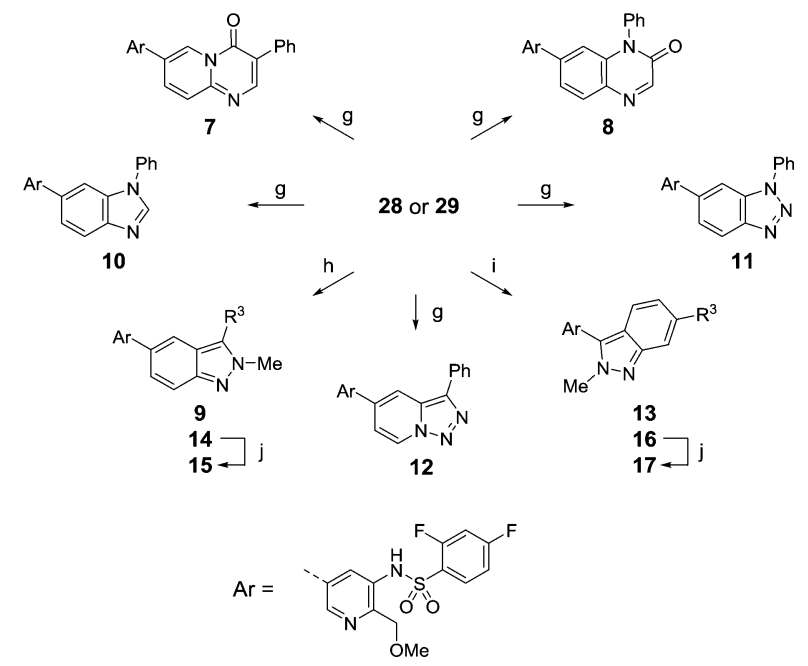

${ }^{a}$ Reagents and conditions: (a) (1) $\mathrm{MsCl}, \mathrm{Et}_{3} \mathrm{~N}, \mathrm{CH}_{2} \mathrm{Cl}_{2}, 0{ }^{\circ} \mathrm{C}$ to r.t.; (2) 2,4-difluorothiophenol, $i$ - $\mathrm{Pr}_{2} \mathrm{NEt}$, THF, $0{ }^{\circ} \mathrm{C}$ to r.t.; (3) $\mathrm{mCPBA}$, $\mathrm{CH}_{2} \mathrm{Cl}_{2}, 0{ }^{\circ} \mathrm{C}$ to r.t.; (b) (1) $\mathrm{NaH}, \mathrm{CH}_{3} \mathrm{I}$, THF, $0{ }^{\circ} \mathrm{C}$; (2) 2,4difluorobenzene-1-sulfonyl chloride, DMAP, pyridine, $60{ }^{\circ} \mathrm{C}$ then $4 \mathrm{M}$ $\mathrm{NaOH}, 1$,4-dioxane, $\mathrm{H}_{2} \mathrm{O}, 90{ }^{\circ} \mathrm{C}$; (c) (1) 2,6-dimethoxybenzylamine, DMF, $120{ }^{\circ} \mathrm{C}$, MW; (2) $\mathrm{NaBH}_{4}, \mathrm{MeOH}, 0{ }^{\circ} \mathrm{C}$ to r.t.; (3) $\mathrm{NaH}, \mathrm{CH}_{3} \mathrm{I}$, THF, $0{ }^{\circ} \mathrm{C}$ to r.t.; (4) 2,4-difluorobenzene-1-sulfonyl chloride, DMAP, pyridine, $60{ }^{\circ} \mathrm{C}$; (d) (1) trichloroisocyanuric acid, $\mathrm{PhCONH}_{2}, \mathrm{CHCl}_{3}$, $75^{\circ} \mathrm{C}$; (2) $c$ - $\mathrm{PrOH}, \mathrm{NaH}$, THF, r.t. then $\mathrm{H}_{2} \mathrm{O}$, r.t.; (3) DPPA, $\mathrm{Et}_{3} \mathrm{~N}$, $t$ $\mathrm{BuOH}$, toluene, $100{ }^{\circ} \mathrm{C}$; (4) $\mathrm{TFA}, \mathrm{CHCl}_{3}$, r.t.; (5) 2,4difluorobenzene-1-sulfonyl chloride, pyridine, $60{ }^{\circ} \mathrm{C}$ then $4 \mathrm{M}$ $\mathrm{NaOH}$, 1,4-dioxane, $\mathrm{H}_{2} \mathrm{O}, 60{ }^{\circ} \mathrm{C} ; \quad(6)$ (Bpin) $)_{2}, \mathrm{PdCl}_{2}$ (dppf)$\mathrm{CH}_{2} \mathrm{Cl}_{2}$, KOAc, 1,4-dioxane, $100{ }^{\circ} \mathrm{C}$; (e) (Bpin) $)_{2}, \mathrm{PdCl}_{2}$ (dppf)$\mathrm{CH}_{2} \mathrm{Cl}_{2}, \mathrm{KOAc}, 1,4$-dioxane, $100{ }^{\circ} \mathrm{C}$; (f) 3-Bpin-5- $\mathrm{R}^{2}-6-\mathrm{R}^{1}$-pyridine or 3-Br-5- $\mathrm{R}^{2}-6-\mathrm{R}^{1}$-pyridine, $\mathrm{PdCl}_{2}$ (dppf)- $\mathrm{CH}_{2} \mathrm{Cl}_{2}, \mathrm{Cs}_{2} \mathrm{CO}_{3}$, 1,4-dioxane, $\mathrm{H}_{2} \mathrm{O}, 100{ }^{\circ} \mathrm{C}$; (g) 29, corresponding aryl bromide, ${ }^{18}$ (XPhos)Pd-G1, $\mathrm{K}_{3} \mathrm{PO}_{4}$, 1,4-dioxane, $\mathrm{H}_{2} \mathrm{O}, 100{ }^{\circ} \mathrm{C}$, MW (h) 28, corresponding arylBpin, ${ }^{19} \mathrm{PdCl}_{2}$ (amphos), $1.5 \mathrm{M} \mathrm{K}_{2} \mathrm{CO}_{3}$, 1,4-dioxane, $100{ }^{\circ} \mathrm{C}$; (i) (1) 29, corresponding aryl iodide, ${ }^{20} \mathrm{PdCl}_{2}(\mathrm{dppf})-\mathrm{CH}_{2} \mathrm{Cl}_{2}, 1.5 \mathrm{M}$ $\mathrm{K}_{2} \mathrm{CO}_{3}, 1,4$-dioxane, $100{ }^{\circ} \mathrm{C}$; $(2) \mathrm{PhB}(\mathrm{OH})_{2}$ or 2-(3,6-dihydro- $2 \mathrm{H}$ pyran-4-yl)-4,4,5,5-tetramethyl-1,3,2-dioxaborolane, $\mathrm{PdCl}_{2}$ (dppf)$\mathrm{CH}_{2} \mathrm{Cl}_{2}, 1.5 \mathrm{M} \mathrm{K}_{2} \mathrm{CO}_{3}$, 1,4-dioxane, $100{ }^{\circ} \mathrm{C}$; (j) $10 \% \mathrm{Pd}(\mathrm{OH})_{2} / \mathrm{C}$, $\mathrm{H}_{2}(1 \mathrm{~atm})$, THF, $\mathrm{MeOH}$, r.t. (a)

\begin{tabular}{ccccccc}
\hline \multicolumn{3}{c}{ Enzyme $\left(\mathrm{IC}_{50}, \mathrm{nM}^{a}\right.$} & & \multicolumn{2}{c}{$\mathrm{LE}^{b}$} & \multicolumn{2}{c}{ Replicon } \\
$\alpha$ & $\beta$ & $\alpha$ & & $\beta$ & $\left(\mathrm{PI} 4 \mathrm{KIII}^{\alpha}\right)$ & \multicolumn{2}{c}{${ }^{\alpha}, \mathrm{nM}^{a}{ }^{a}$} & $1 \mathrm{~b}$ \\
\hline $\mathbf{0 . 3 1}$ & $\mathbf{2 2 0}$ & $\mathbf{2 4 0}$ & $\mathbf{1 4 0 0}$ & $\mathbf{0 . 3 4}$ & $\mathbf{1 0}$ & $\mathbf{6 . 8}$ \\
\hline${ }^{a}$ Values of $\mathrm{IC}_{50}$ and $\mathrm{EC}_{50}$ are mean values determined from at least three
\end{tabular}
replicates. ${ }^{b} \mathrm{LE}=-1.37 \log \mathrm{IC}_{50}\left(\mathrm{PI} 4 \mathrm{KIII}{ }^{\alpha}\right) /$ number of heavy atoms.

(b)

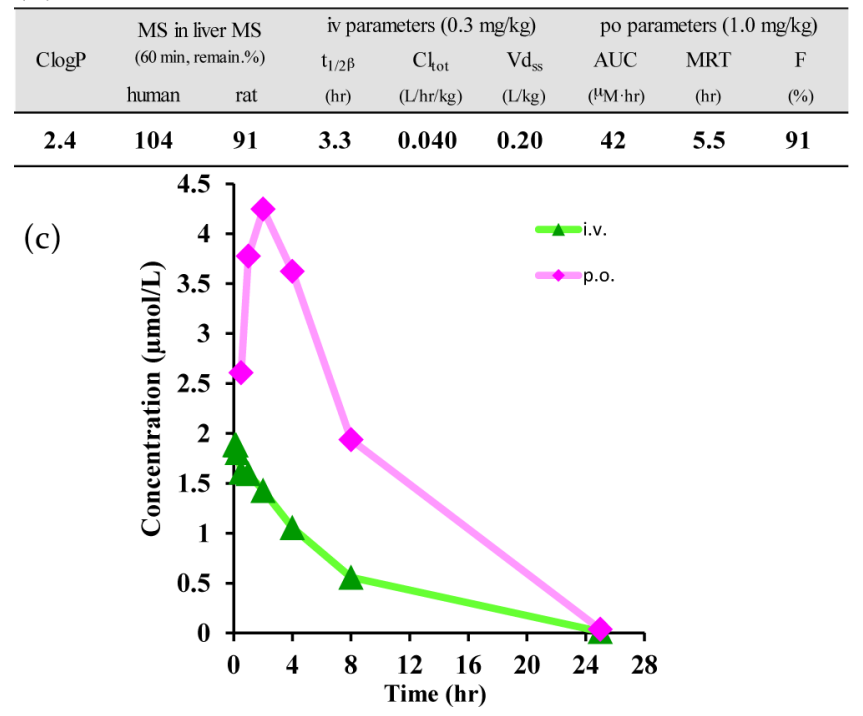

Figure 3. Profiles of 22. (a) In vitro pharmacological profiles of 22 were shown in tabular form. (b) Both in vitro ADME parameters and rat $\mathrm{PK}$ parameters for $\mathbf{2 2}$ were shown in tabular form. (c) Pharmacokinetic curve of $\mathbf{2 2}$ in rat. See the Supporting Information for detailed protocol.

alkyl group such as tetrahydropyran resulted in reduced PI4KIII $\alpha$ potency). ${ }^{11}$ Needless to say, brief optimization of the rest of the molecules such as $\mathbf{1 5}$ and 17 will lead to generation of more diverse PI4KIII $\alpha$ inhibitors, although the details are beyond the scope of this report.

The PI4KIII $\alpha$ inhibitors shown in this letter were synthesized following a method highlighted in Scheme 1. The route was simple and a diverse set of compounds was prepared through Suzuki-type cross coupling in a convergent manner.

Given its superb PI4KIII $\alpha$ potency along with good on-target selectivity, additional assays were conducted with representative compound 22 (Figure 3). First, two additional counter assays were carried out to further confirm its nonpromiscuous character, and over 800-fold selectivity was also observed against two typical lipid kinases, $\mathrm{PI} 3 \mathrm{~K} \alpha$ and $\mathrm{PI} 3 \mathrm{~K} \beta$. More importantly, 22 exhibited a low nanomolar $\mathrm{EC}_{50}$ in both $1 \mathrm{~b}$ and 1a replicon assays, thus demonstrating broad-spectrum inhibition of HCV genotypes, which was originally expected and now seems highly plausible. Good physicochemical properties as well as high metabolic stability were also notable, leading to preferable plasma half-life and excellent oral bioavailability for 22 .

In summary, a novel "head-to-tail" approach has been developed to discover selective PI4KIII $\alpha$ inhibitors. After a concise investigation, we have successfully identified several classes of compounds showing a single-digit nanomolar value of $\mathrm{IC}_{50}$ against PI4KIII $\alpha$. They are composed of different core 
structures, which could further multiply the diversity after the successive tuning of the accompanying substituents. We believe this method is rational yet truly simple and that this overall concept will also be applicable to general kinase programs.

\section{ASSOCIATED CONTENT}

\section{S Supporting Information}

The Supporting Information is available free of charge on the ACS Publications website at DOI: 10.1021/acsmedchemlett.6b00232.

Synthetic procedures, experimental data, assay procedures, and PK profiles of 22 (PDF)

\section{AUTHOR INFORMATION}

\section{Corresponding Author}

*Phone: +81-72-681-9700. E-mail: makoto.shiozaki@jt.com.

Notes

The authors declare no competing financial interest.

\section{ACKNOWLEDGMENTS}

We thank Dr. Hiromasa Hashimoto for support.

\section{ABBREVIATIONS}

NS5A, hepatitis C virus (HCV) nonstructural protein 5A; PI3K $\gamma$, phosphoinositide 3-kinase gamma; PK, pharmacokinetics; LE, ligand efficiency

\section{REFERENCES}

(1) Gower, E.; Estes, C.; Blach, S.; Razavi-Shearer, K.; Razavi, H. Global epidemiology and genotype distribution of the hepatitis $\mathrm{C}$ virus infection. J. Hepatol. 2014, 61, S45-S57.

(2) Hepatitis C. http://www.who.int/mediacentre/factsheets/fs164/ en/ (accessed by May 17, 2016).

(3) Perz, J. F.; Armstromg, G. L.; Farrington, L. A.; Hutin, Y. J. F.; Bell, B. P. The contributions of hepatitis $B$ virus and hepatitis $C$ virus infections to cirrhosis and primary liver cancer worldwide. J. Hepatol. 2006, 45, 529-538.

(4) Brown, R. S., Jr. Hepatitis C and liver transplantation. Nature 2005, 436, 973-978.

(5) Liang, T. J.; Ghany, M. G. Therapy of Hepatitis C-Back to the Future. N. Engl. J. Med. 2014, 370, 2043-2047.

(6) Hahn, T. V.; Ciesek, S.; Manns, M. P. Arrest All AccessoriesInhibition of Hepatitis C Virus by Compounds that Target Host Factors. Discovery Med. 2011, 12, 237-244.

(7) Balla, A.; Balla, T. Phosphatidylinositol 4-kinases: old enzymes with emerging functions. Trends Cell Biol. 2006, 16, 351-361.

(8) Berger, K. L.; Cooper, J. D.; Heaton, N. S.; Yoon, R.; Oakland, T. E.; Jordan, T. X.; Mateu, G.; Grakoui, A.; Randall, G. Roles for endocytic trafficking and phosphatidylinositol 4-kinase III alpha in hepatitis C virus replication. Proc. Natl. Acad. Sci. U. S. A. 2009, 106, 7577-7582.

(9) Reiss, S.; Harak, C.; Romero-Bery, I.; Radujkovic, D.; Klein, R.; Ruggieri, A.; Rebhan, I.; Bartenschlager, R.; Lohmann, V. The Lipid Kinase Phosphatidylinositol-4 Kinase III Alpha Regulates the Phosphorylation Status of Hepatitis C Virus NS5A. PLoS Pathog. 2013, 9, e1003359.

(10) Altan-Bonnet, N.; Balla, T. Phosphatidylinositol 4-kinases: hostages harnessed to build panviral replication platforms. Trends Biochem. Sci. 2012, 37, 293-302.

(11) Leivers, A. L.; Tallant, M.; Shotwell, J. B.; Dickerson, S.; Leivers, M. R.; McDonald, O. B.; Gobel, J.; Creech, K. L.; Strum, S. L.; Mathis, A.; Rogers, S.; Moore, C. B.; Botyanszki, J. Discovery of Selective Small Molecule Type III Phosphatidylinositol 4-Kinase Alpha (PI4KIII $\alpha$ ) Inhibitors as Anti Hepatitic C (HCV) Agents. J. Med. Chem. 2014, 57, 2091-2106.
(12) Onions, S. T.; Ito, K.; Charron, C. E.; Brown, R. J.; Colucci, M.; Frickel, F.; Hardy, G.; Joly, K.; King-Underwood, J.; Kizawa, Y.; Knowles, I.; Murray, P. J.; Novak, A.; Rani, A.; Rapeport, G.; Smith, A.; Strong, P.; Taddei, D. M.; Williams, J. G. Discovery of Narrow Spectrum Kinase Inhibitors: New Therapeutic Agents for the Treatment of COPD and Steroid-Resistant Asthma. J. Med. Chem. 2016, 59, 1727-1746.

(13) Waring, M. J.; Arrowsmith, J.; Leach, A. R.; Leeson, P. D.; Mandrell, S.; Owen, R. M.; Pairaudeau, G.; Pennie, W. D.; Pickett, S. D.; Wang, J.; Wallace, O.; Weir, A. An analysis of the attrition of drug candidates from four major pharmaceutical companies. Nat. Rev. Drug Discovery 2015, 14, 475-486.

(14) Cushing, T. D.; Metz, D. P.; Whittington, D. A.; McGee, L. R. PI3K $\delta$ and $\mathrm{PI} 3 \mathrm{~K} \gamma$ as Targets for Autoimmune and Inflammatory Diseases. J. Med. Chem. 2012, 55, 8559-8581.

(15) Knight, S. D.; Adams, N. D.; Burgess, J. L.; Chaudhari, A. M.; Darcy, M. G.; Donatelli, C. A.; Luengo, J. I.; Newlander, K. A.; Parrish, C. A.; Ridgers, L. H.; Sarpong, M. A.; Schmidt, S. J.; Van Aller, G. S.; Carson, J. D.; Diamond, M. A.; Elkins, P. A.; Gardiner, C. M.; Garver, E.; Gilbert, S. A.; Gontarek, R. R.; Jackson, J. R.; Kershner, K. L.; Luo, L.; Raha, K.; Sherk, C. S.; Sung, C.-M.; Sutton, D.; Tummino, P. J.; Wegrzyn, R. J.; Auger, K. R.; Dhanak, D. Discovery of GSK2126458, a Highly Potent Inhibitor of PI3K and the Mammalian Target of Rapamycin. ACS Med. Chem. Lett. 2010, 1, 39-43.

(16) PI4KIII $\beta$ homology model shown in Figure $2 \mathrm{~b}$ is a homology model (with no ligand molecule). We observed that when creating the PI4KIII $\beta$ complex model with the compound $\mathbf{5}$ in the same manner as the complex model of PI4KIII $\alpha$, compound $\mathbf{5}$ was shifted to the opposite direction from the affinity pocket, indicating that the methoxymethyl moiety was too large for PI4KIII $\beta$.

(17) Peters, J.-U.; Schnider, P.; Mattei, P.; Kansy, M. Pharmacological Promiscuity: Dependence on Compound Properties and Target Specificity in a Set of Recent Roche Compounds. ChemMedChem 2009, 4, 680-686.

(18) The corresponding arylbromide are as follows: SI-17 for 7, SI23 for 8, SI-24 for 10, SI-25 for 11, and SI-22 for 12. Please also see the Supporting Information.

(19) The corresponding arylBpin are as follows: SI-27 for 9 and SI30 for 14.

(20) SI-32 is the corresponding aryliodide for synthesis of $\mathbf{1 3}$ as well as 16 . 